\title{
A Self-Inserted Foreign Body in the Urinary Bladder and Urethra
}

\author{
Hakan Tuncer ${ }^{1}$, Hatice Karacam ${ }^{1}$, Betul Cam ${ }^{1}$ \\ 1. Emergency Medicine, Bağcılar Training and Research Hospital, Istanbul, TUR \\ Corresponding author: Hatice Karacam, kutruba@hotmail.com
}

\begin{abstract}
Foreign objects in the lower genitourinary system are a rare urological emergency often associated with selferoticism, drug intoxication, or psychiatric illness. In addition to clinical examination, multiple imaging modalities such as X-ray, ultrasound, computed tomography, and magnetic resonance imaging have been used for the diagnosis of foreign bodies. Surgical exploration and endoscopic extraction are the main approaches to the treatment. Here, we present the case of a 37-year-old male who presented to the emergency department with penile and urethral pain caused by an electrical wire inserted into the urethra. The electrical wire was protruding $15 \mathrm{~cm}$ from the urethral meatus. A $50 \mathrm{~cm}$ long cable was extracted from the urethra and urinary bladder under regional anesthesia. This case is remarkable for the length of the foreign body and the depth to which it was inserted reaching into the urinary bladder. Emergencies related to sexuality or unconventional sexual preferences can lead to avoidance or delay of medical treatment, which, in turn, can result in a higher risk of complications. The examining doctor should be sensitive to secretive and insecure behavior and should be considerate of the patient's privacy to facilitate a thorough physical examination.
\end{abstract}

Review began 06/15/2021 Review ended 07/03/2021 Published 07/11/2021

(๑) Copyright 2021

Tuncer et al. This is an open access article distributed under the terms of the Creative Commons Attribution License CC-BY 4.0., which permits unrestricted use, distribution, and reproduction in any medium, provided the original author and source are credited.
Categories: Emergency Medicine, Radiology, Urology

Keywords: urinary bladder, urethra, radiology, physical examination, foreign body

\section{Introduction}

The most common complaints associated with foreign objects in the genitourinary organs include pelvic pain, hematuria, dysuria, urinary frequency, strangury, urinary retention, and secondary stones [1-7]. A wide variety of objects have been reported to be self-inserted into the lower genital organs such as pins, electrical wires, screws, olive seeds, or ballpoint pens [2-6]. In $63 \%$ of such cases, the patients are males of different ages [8]. Clinical history, physical examination, and imaging tests help physicians diagnose foreign objects in the human body $[9,10]$. Some of the behavior resulting in the self-insertion of such objects is caused by mental health illness, senility, drug intoxication, and autoerotic stimulation [7]. In non-psychotic mental disorders where sexual gratification is achieved by unusual and potentially harmful actions, habitualization is common [11,12]. Here, we report the case of a 37-year-old male patient who presented to our Emergency Department with transurethral insertion of a $50 \mathrm{~cm}$ long electrical wire into the urinary bladder.

\section{Case Presentation}

A 37-year-old male patient presented to the Emergency Department complaining of severe penile pain. Physical examination revealed an electrical wire protruding $15 \mathrm{~cm}$ from the urethral meatus (Figures 1, 2). 


\section{Cureus}

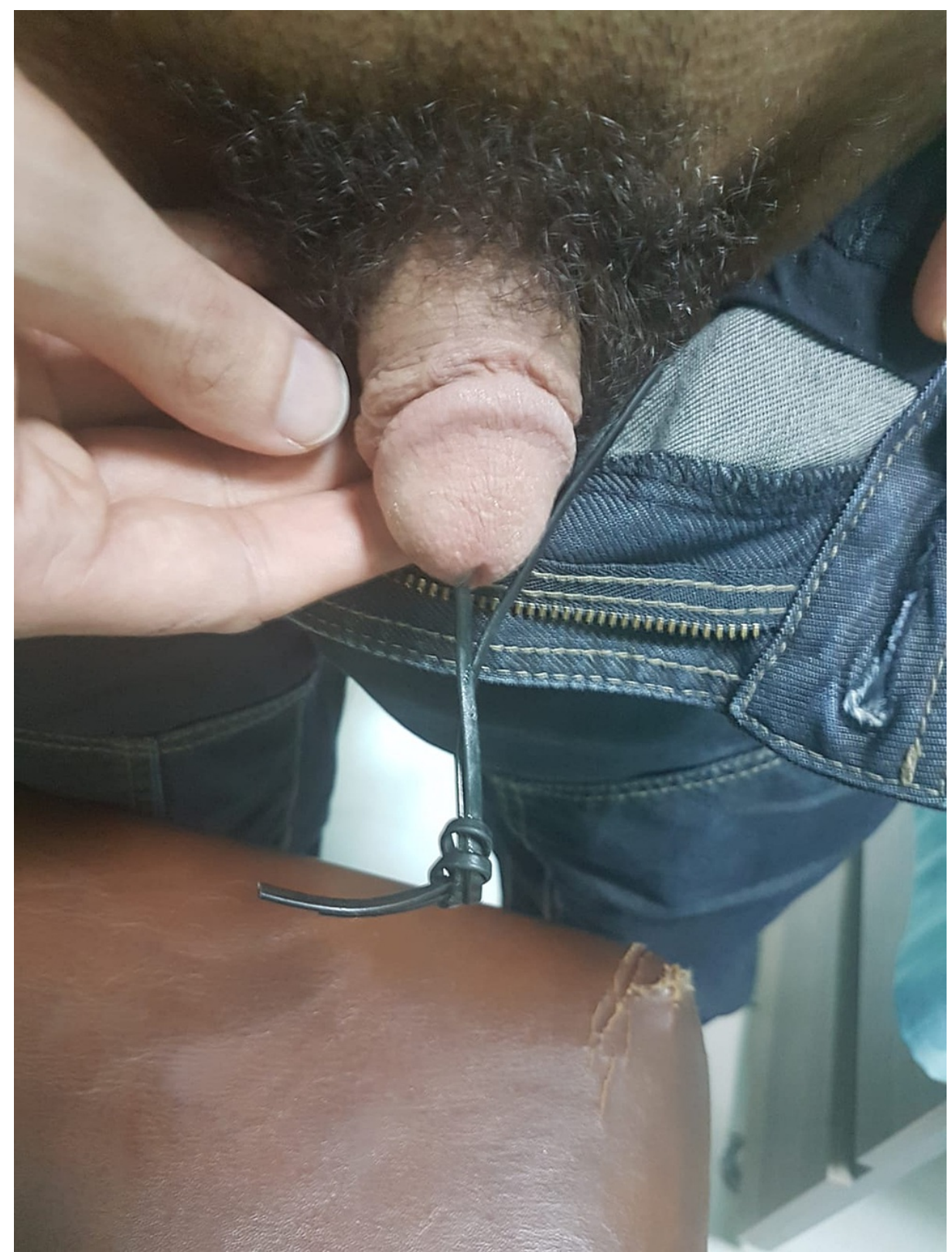

FIGURE 1: A foreign body in the urethra. 


\section{Cureus}

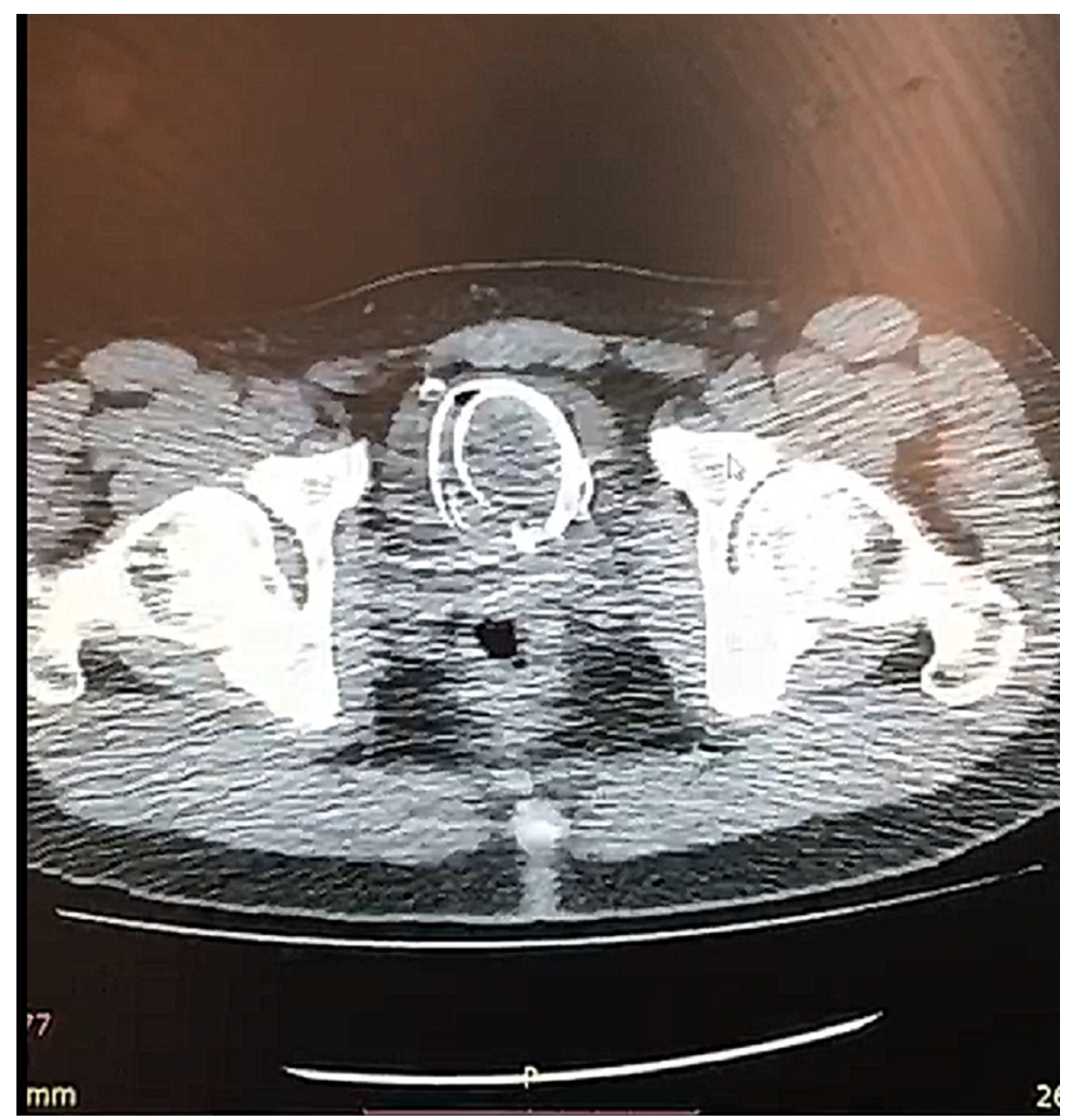

FIGURE 2: The cable demonstrates a circular shape in the urinary bladder.

The patient had no significant medical history. He disclosed the reason for the self-insertion of the wire as sexual arousal. A non-enhanced computed tomography scan (CT) of the pelvic cavity revealed a circular wire inside the urinary bladder. A urethral extraction was immediately scheduled by the urologist and the wire was extracted under local anesthesia (Figure 3). 


\section{Cureus}

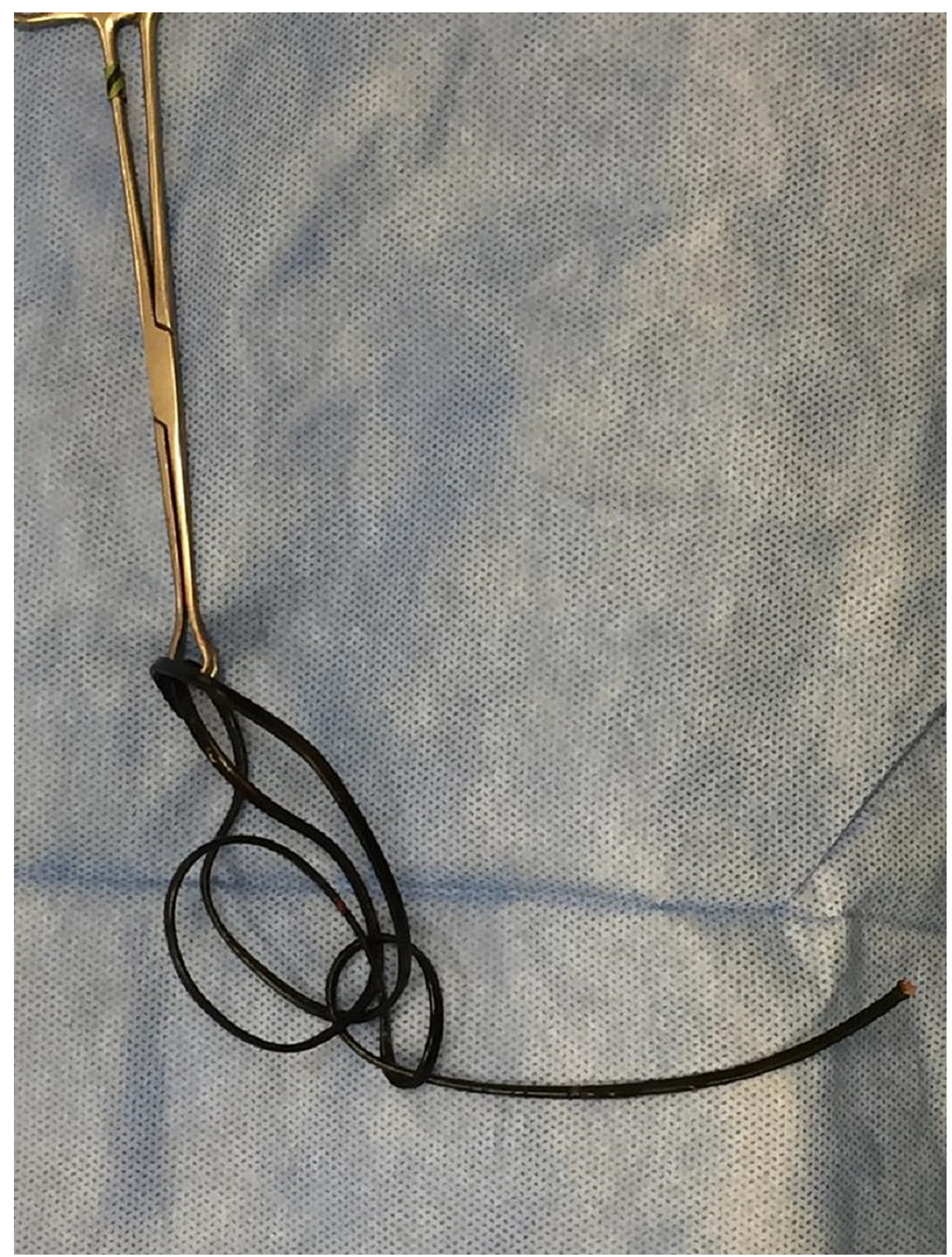

FIGURE 3: The extracted electrical wire.

The wire had a total length of about $65 \mathrm{~cm}, 50 \mathrm{~cm}$ of which had been lodged inside the body. A follow-up plan was scheduled with the urology and psychiatric departments.

\section{Discussion}

Several different foreign objects have been previously reported to be self-inserted into the lower genitourinary tract, such as cables, screws, nuts, metallic tongue cleaner, and pens [1-7]. Forcing such objects into bodily orifices can be harmful. X-ray, ultrasound, CT, and magnetic resonance imaging are the imaging tests of choice to determine the presence of such objects. X-rays and ultrasounds are cheaper and more accessible in many clinics [10]. Endoscopic and surgical interventions are used to remove foreign bodies [13-16]. An endoscopic procedure is a fast and recommended method for removing foreign bodies under local anesthesia. Open surgery may be required for sharp and irregularly shaped objects. In our case, a looped circular wire was detected in the urinary bladder on a CT scan and was successfully removed under local anesthesia.

\section{Conclusions}

Self-insertion of foreign bodies into the urinary tract is rather rare in emergency medicine practice. Imaging is necessary to determine the urethral location, shape, and size of the foreign objects. Urethral stenosis could develop following surgical interventions due to tissue damage. Tetanus prophylaxis and antibiotic 
treatment are required after the removal of the foreign body. Further, psychiatric counseling should be offered for habitual cases.

\section{Additional Information \\ Disclosures}

Human subjects: Consent was obtained or waived by all participants in this study. Conflicts of interest: In compliance with the ICMJE uniform disclosure form, all authors declare the following: Payment/services info: All authors have declared that no financial support was received from any organization for the submitted work. Financial relationships: All authors have declared that they have no financial relationships at present or within the previous three years with any organizations that might have an interest in the submitted work. Other relationships: All authors have declared that there are no other relationships or activities that could appear to have influenced the submitted work.

\section{References}

1. Ahmed MHS, Pawar PW, Sawant AS, Sakharani J, Arora A, Patil SR, Patel D: Foreign body in urinary bladder: our experience and review of literature. Int Surg J. 2019, 6:4327-31. 10.18203/2349-2902.isj20195388

2. Bayraktar Z, Albayrak S: A self-inflicted male urethral/vesical foreign body (olive seed) causing complete urinary retention. Urol Case Rep. 2018, 16:83-5. 10.1016/j.eucr.2017.11.023

3. Mitterberger M, Peschel R, Frauscher F, Pinggera GM: Allen key completely in male urethra: a case report . Cases J. 2009, 2:7408. 10.4076/1757-1626-2-7408

4. Dinesh A, Singh A, Neogi S: Tongue cleaner, an unusual foreign body in the urethra: a case report . Australas Med J. 2013, 6:508-10. 10.4066/AMJ.2013.1851

5. Cam B, Tuncer H, Uzun O, Uysal E: Nail scissor as a rare foreign body in the urethra: case report . Cureus. 2019, 11:e3851. 10.7759/cureus.3851

6. Trehan RK, Haroon A, Memon S, Turner D: Successful removal of a telephone cable, a foreign body through the urethra into the bladder: a case report. J Med Case Rep. 2007, 1:153. 10.1186/1752-1947-1-153

7. Mahadevappa N, Kochhar G, Vilvapathy KS, Dharwadkar S, Kumar S: Self-inflicted foreign bodies in lower genitourinary tract in males: our experience and review of literature. Urol Ann. 2016, 8:338-42. 10.4103/0974-7796.184904

8. John J, Kesner K: Urethral polyembolokoilamania: not a bread-and-butter issue . Ther Adv Urol. 2021, 13:17562872211022866. 10.1177/17562872211022866

9. Simangunsong AI, Pramod SV: Intravesical foreign object: a case report of autoerotism . Int J Surg Case Rep. 2020, 77:515-8. 10.1016/j.ijscr.2020.11.079

10. Gupta N, Goyal P, Sharma K, et al.: Penile fracture: role of ultrasound. Transl Androl Urol. 2017, 6:580-4. 10.21037/tau.2017.03.38

11. Padmanabhan P, Hutchinson RC, Reynolds WS, Kaufman M, Scarpero HM, Dmochowski RR: Approach to management of iatrogenic foreign bodies of the lower urinary tract following reconstructive pelvic surgery. J Urol. 2012, 187:1685-90. 10.1016/j.juro.2011.12.081

12. Bansal A, Yadav P, Kumar M, Sankhwar S, Purkait B, Jhanwar A, Singh S: Foreign bodies in the urinary bladder and their management: a single-centre experience from North India. Int Neurourol J. 2016, 20:2609. 10.5213/inj.1632524.262

13. Barzilai M, Cohen I, Stein A: Sonographic detection of a foreign body in the urethra and urinary bladder . Urol Int. 2000, 64:178-80. 10.1159/000030524

14. Rahman NU, Elliott SP, McAninch JW: Self-inflicted male urethral foreign body insertion: endoscopic management and complications. BJU Int. 2004, 94:1051-3. 10.1111/j.1464-410X.2004.05103.X

15. Agha RA, Borrelli MR, Farwana R, Koshy K, Fowler AJ, Orgill DP: The SCARE 2018 statement: updating consensus Surgical CAse REport (SCARE) guidelines. Int J Surg. 2018, 60:132-6. 10.1016/j.ijsu.2018.10.028

16. Park S, Moon KH, Kim SH, Kim DY, Cho YW, Cho SJ, Park S: Needles as urethral foreign body in a child: successful removal using a new method with a laparoscopic needle holder. Urology. 2013, 81:188-90. 10.1016/j.urology.2012.09.005 